\title{
Research on the Improvement of the Socialist Education Base's Educational function with Chinese Characteristics
}

\author{
Jiangping Liu \\ Fire Academy of Public Security Department. Yunnan Kunming. 650208
}

Keywords: Education base, Socialist education base with Chinese characteristics

\begin{abstract}
Education is the rejuvenation of the Chinese nation, and the cornerstone of social progress. It is the fundamental way of improving national quality and promoting people's all-round development, entrusted with the hundreds of millions of families hope for a better life, and carrying the hopes of the great rejuvenation of the Chinese nation. The socialist education with Chinese characteristics is an important part of the socialism with Chinese characteristics. We applied the experts' consultation to evaluate the reform plan of socialist education with Chinese characteristics. The experts' influence degree and questionnaire was analyzed in the study. The results indicate the reform plan was executable. It adheres to the Marxist basic theory of education, and embodies the Chinese national conditions. At present, the Chinese characteristic socialism education foundation is kept in the questions.
\end{abstract}

\section{Introduction}

In today's world, with the increasingly fierce competition in comprehensive national strength and scientific and technological progress with each passing day, human resources become the strategic resources to promote economic and social development. Talent becomes the key to the competitiveness of the country ${ }^{[1]}$. Facing the more intense challenges, we only insist on giving priority to the development of education, in order to achieve in advance and development of human resources, cultivate and bring up hundreds of millions of high-quality workers, tens of millions of specialized personnel and a large number of top-notch innovative personnel. It provides strong talents guarantee and intellectual support to promote the scientific development of economy and society ${ }^{[2]}$.

To cultivate all-round development of socialist builders and successors is the essential requirement of our country's education, and also is the fundamental mission of the socialist educational development road with Chinese characteristics ${ }^{[3]}$. In the face of unprecedented opportunities and challenges, we must hold high the great banner of socialism with Chinese characteristics, unswervingly take the road of socialist education with Chinese characteristics, and constantly promote the scientific development of the cause of education.

\section{The objective of the Socialist educational base with Chinese Characteristics}

The education function refers to "education activities and the system will influence the development of body and society" ${ }^{[4]}$. Socialist education base with Chinese characteristics, through the development of the educational activities, strengthen the building of socialism with Chinese characteristics, and enhance the sense of responsibility and mission to actively participate in the construction of the motherland's modernization.

(1) A firm belief in the construction of social justice with Chinese characteristics

With the development of science and technology, network is filled full "advanced culture and the backward culture of struggle, co-occurrence of the elite culture and the public, literary tradition and modern culture of surging, the main stream culture and sub culture of penetration." ${ }^{[5]}$ In this kind of shape potential, firmly established the public building of socialism with Chinese characteristics is particularly important to the letter read. In the education base at all levels across the country, it has the Chinese excellent tradition culture for thousands of years. Through the visit, to arouse the national consciousness, national unity consciousness, suffering consciousness and responsibility 
consciousness. It is not enough to use of these resources to carry out educational activities, so that people need to fully understand the importance of the socialist core values of China's modernization.

(2) Enhance the sense of historical identity and national pride

There are a lot of history culture and education base in our country education base, such as $\mathrm{Yu}$ Ling, former residence of Confucius, the Dunhuang Mogao Grottoes, Jiang Yan water engineering, Jia Yu Guan, eight of Long Ling City and the museum. Education base carrying China's thousands of year's culture, the culture embodies the Chinese nation's self-reliance spirit pursuit and timeless spiritual wealth ${ }^{[6]}$. It is the solid foundation of the development of socialist advanced culture, and the Chinese nation building has an important support for the spiritual home. Making full use of these educational resources will enhance the public's sense of identity and pride of the Chinese nation's culture.

(3) Enhance the sense of responsibility and mission of the visitors to join the cause of modernization

Education of socialism with Chinese characteristics is to stimulate the education of patriotism, enhance the national current policy approval, setting up the home construction and better firm faith. And then it translated into the actual action of nation building. So it just wakes education of national pride and pride sense is not enough. It need through the national education to correct understanding of the current situation of the world and domestic situation, and understand the experience and lessons in the process of China's modernization drive ${ }^{[7]}$. Using the scientific and rational methods to analyze the gap between our country and the advanced countries, and to understand the significance of the national policies, and the policies to promote the modernization of our country, and actively invest in the great cause of socialist modernization and national rejuvenation.

\section{The improvement of the Educational Function of \\ Socialist Education with Chinese Characteristics}

Expert evaluation was applied in the process of evaluation and improvement of the present education method and materials of the Socialist education with Chinese characteristics.

(1) The requirement of the experts

The experts were chosen based on the following criteria: College degree and above; from one of the practice socialist education facility; has more than 10 years working experience in this field; with the intermediate and above titles; has a certain enthusiasm and willing to participate in this study.

(2) The number of experts

In general, the accuracy of the results of expert consultation and the number of people to participate in the consultation showed a functional relationship, that is, the forecast precision with the increase in the number of participants to improve, and research shows that when the number of consulting close to 15 people, and then into a step to increase the number of counseling on the prediction accuracy is not affected by [45]. Considering the purpose and characteristics of the teaching management and socialist education, 18 more senior experts in the field of education experts consulting team, including the school practice teaching management experts, community practice teaching base management experts, prized socialist education base in other provinces.

(3) Design of the questionnaire

In accordance with the main content of the "teaching plan", the research group designed the questionnaire. After the pre-survey with 3 experts, the expert advice form and the basic information questionnaire were identified. The first round of the expert advice questionnaire has 46 questions, which involves the 7 necessary questions, 32 rational questions and 7 feasible questions. According to the reply to the first round of expert consultation opinions and suggestions on the content of the plan of teaching integration, modify and add the entries of "practice base construction idea, goal and practice content". In the second round of expert consultation questionnaire, the Communist Party of China set the 42 problems, necessity of seven, rationality of 28 and feasibility of 7 . All questions are set up by the research group, which is simple, accurate and necessary for the. In order to further 
understand the experts on the contents of this specification is not mentioned in the comments and suggestions, in the form of a consultation table set up an open question. (2) the experts' situation questionnaire includes the basic situation of the investigation experts, the expert knowledge of the content of the consultation and the basis for judging.

(4) Experts consultation

Two rounds of consultation with the letter mailed, personally issued, e-mail and recovery of the expert consultation questionnaire. First round of consultation questionnaire issued a total of 22 accessions, recycling 19 copies, questionnaire accompanied by details about the research background, purpose and method is introduced. After the first round of questionnaires, the research team on the recovery of the questionnaire summary, sorting out and analyzing, and according to the results of the analysis to revise the education implementation of the program content, the main views and the second round of expert consultation questionnaire sent to the first round of expert consultation to give the reply of 19 experts, in the second round of expert consultation, the recovery of 18.

(5) Statistical analysis

For education implementation of the program content, consultation questionnaire set up three aspects of necessity, rationality and feasibility of the evaluation problem, the importance degree of each question according to Likert five metric method (Likert5-SCale) points for five grades: quite necessary / is reasonable / quite feasible (5 points), necessary / reasonable / feasible (4 points), general (3 points), unnecessary / unreasonable / not feasible (2 points), is not necessary / is not reasonable / is not feasible (1 point). Taking into account the different degree of each expert authority, need to understand each expert for each indicator familiar degree and judgment basis, the understanding degree into five grades: very familiar, familiar, familiar medium, not familiar, very familiar, degree coefficient were assigned to 1.0 and $0.8,0.6,0.4,0.2$. According to the conventional judgment is divided into practical experience, theoretical analysis, reference materials, intuitive sense and other 4 categories, the impact is divided into large, medium and small, respectively, given the different values, as shown in table 1 .

Table 1 Judgment basis and its influence degree

\begin{tabular}{llll}
\hline \multirow{2}{*}{ Judgment Basis } & \multicolumn{3}{c}{ The influential degree on experts } \\
& Light & Medium & Heavy \\
\hline Practical experience & 0.5 & 0.4 & 0.3 \\
Theoretical analysis & 0.3 & 0.2 & 0.1 \\
Literature review & 0.1 & 0.1 & 0.05 \\
Intuiation & 0.1 & 0.1 & 0.05 \\
\hline
\end{tabular}

\section{Results}

(1) Experts’ positive coefficient

Experts' positive coefficient refers to the experts' level of interest in this study. It is measured by the recycling rate of the expert advice sheet. The calculation method is feedback opinions of experts (Mj) accounts for the total number of experts (M). Two rounds of experts' consultation were conducted in this study. 22 questionnaires were sent in first round and 19 copies were sent in the second round. The first round recovered 19 copies, the second round recovered 19 copies. The experts' positive coefficients were $86.4 \%$ and $94.7 \%$, as shown in table 2 . 
Table 2 Questionnaire Received of Two Rounds Expert Consultation

\begin{tabular}{|c|c|c|c|c|c|c|}
\hline \multirow{2}{*}{ Specialty } & \multicolumn{2}{|c|}{ Issued } & \multicolumn{2}{|c|}{ Recovered } & \multicolumn{2}{|c|}{ Recovery rate (\%) } \\
\hline & $1 \mathrm{st}$ & 2ed & $1 \mathrm{st}$ & 2ed & $1 \mathrm{st}$ & 2ed \\
\hline Practical education & 5 & 2 & 2 & 1 & $40 \%$ & $50 \%$ \\
\hline Education base management & 11 & 11 & 11 & 11 & $100 \%$ & $100 \%$ \\
\hline Practical education management & 2 & 2 & 2 & 2 & $100 \%$ & $100 \%$ \\
\hline Socialist education & 1 & $\mathbf{i}$ & 1 & $!$ & $100 \%$ & $100 \%$ \\
\hline Socialist Theory & 1 & 1 & 1 & 1 & $100 \%$ & $100 \%$ \\
\hline Socialist education base management & 2 & 2 & 2 & 2 & $100 \%$ & $100 \%$ \\
\hline Summary & 22 & 19 & 19 & 18 & $86.4 \%$ & $94.7 \%$ \\
\hline
\end{tabular}

(2) Demographic factors of experts

The demographic factors of experts were shown in table 3.

Table3 Demographic Factors of Experts

\begin{tabular}{|c|c|c|c|}
\hline & & Experts & Proportion (\%) \\
\hline \multirow{4}{*}{ Education } & Junior colleage & 2 & $11.11 \%$ \\
\hline & Undergraduate & 13 & $72.22 \%$ \\
\hline & Master & 3 & $16.67 \%$ \\
\hline & Doctor & 0 & $0.00 \%$ \\
\hline \multirow{3}{*}{ Title } & Intermediate & 10 & $55.56 \%$ \\
\hline & Deputy senior & 7 & $38.89 \%$ \\
\hline & Senior & 1 & $5.56 \%$ \\
\hline \multirow{6}{*}{ Specialty } & Practical education & 1 & $5.56 \%$ \\
\hline & $\begin{array}{l}\text { Education base } \\
\text { management }\end{array}$ & 11 & $61.11 \%$ \\
\hline & $\begin{array}{l}\text { Practical education } \\
\text { management }\end{array}$ & 2 & $11.11 \%$ \\
\hline & Socialist education & 1 & $5.56 \%$ \\
\hline & Socialist Theory & 1 & $5.56 \%$ \\
\hline & $\begin{array}{l}\text { Socialist education base } \\
\text { management }\end{array}$ & 2 & $11.11 \%$ \\
\hline \multirow{3}{*}{$\begin{array}{l}\text { Working } \\
\text { year }\end{array}$} & Above 31 & 2 & $11.11 \%$ \\
\hline & $21 \sim 30$ & 7 & $38.89 \%$ \\
\hline & $11 \sim 20$ & 9 & $50.00 \%$ \\
\hline
\end{tabular}

(3) Consultation results

The consultation results were shown in table 4 . 
Table 4 Consultation results

\begin{tabular}{cccccr}
\hline & Indicators & Coefficient & $\chi^{2}$ & Df & Sig. \\
\hline Fist round & 46 & 0.150 & 136.413 & 45 & 0.000 \\
Necessity & 7 & 0.202 & 23.107 & 6 & 0.001 \\
Rationality & 32 & 0.076 & 46.154 & 31 & 0.039 \\
Feasibility & 7 & 0.037 & 4.299 & 6 & 0.636 \\
Second round & 42 & 0.174 & 126.664 & 41 & 0.000 \\
Necessity & 7 & 0.162 & 18.102 & 6 & 0.006 \\
Rationality & 28 & 0.135 & 66.512 & 27 & 0.000 \\
Feasibility & 7 & 0.121 & 13.708 & 6 & 0.033 \\
\hline
\end{tabular}

\section{Discussion}

(1) To strengthen the infrastructure construction of socialist education base

Infrastructure construction is an important part of the construction of socialist education base with characteristics. The infrastructure of socialist education base with characteristics contains venue construction, the construction of safety facilities, the construction of service facilities and the construction of educational facilities. Socialist educational base with characteristics of venues is essential condition for education base carrying out educational activities. Therefore, it must be attention at all levels of the education base of venue construction and maintenance, provides a platform for the education base function play.

To strengthen the socialist education base with characteristics construction management. Construction of the management mechanism of socialist educational base relates to inter departmental coordination mechanism, financial management, ensure earmarking and other aspects ${ }^{[9]}$. The construction of education base involves multiple departments, so it must clear the respective responsibilities, responsibility to the people, to ensure that the work of mutual cooperation. Scientific rules and regulations can ensure the long-term effective operation of the education base, and help the education base to fully play the educational function.

Strengthen the website construction of characteristic socialism education base. Network plays a more and more important role in all aspects of social life. The number of Internet users has increased, and the convenience of the Internet has taken root in the hearts of the people. To make full use of Internet resources, and strengthen education base of the website construction, it can help to expand the radiation of the education base. It is not only to increase the number of network stations in the education base, but also to raise the construction quality of the network station of the characteristic socialist educational system.

Strengthen the connotation construction of characteristic socialism education base. Characteristic socialist educational base of connotation construction is the core construction of education base. Only to strengthen the connotation construction of education base, education base in order to more vivid, more attractive. Characteristic socialist education can achieve better effect. The characteristic socialist education base exhibits need to dig deep connotation. Education base itself also needs to strengthen the construction of characteristic. Unique education base in order to attract more people to visit, it is conducive to play the role of the education base.

(2) Encourage the education of the subject and object to effectively utilize the education base

Even if the construction of the socialist educational base has been improved to a considerable degree, socialist educational base must also through educational activities to really play the effect of education. Among them, subject and object of education plays an important role. It cannot be ignored. Practice teaching in all education activities are important, the socialist education also need to encourage education subject to carry out practice teaching activity by the socialist education base. Using the socialist education base to carry out practical teaching is an important link to cultivate the 
independent thinking. It is an important platform to link theory with practice and cultivate students' active learning ability. Organs and units, the caucus organization to combined with the practice and full use of local resources of the socialist education base. It is conducive to give full play to the educational function of socialist education base.

Educational subjects use the socialist education base to carry out educational activities. It is not only to pay more attention to the quantity, but also to pay more attention to the quality of education. Only through effective education activities, it can we play the educational function of the socialist education base.

(3) Establish and perfect the evaluation system of the education effect of the socialist education base

To establish the socialist education base effect evaluation mechanism needs to adhere to the guidance, objectivity, and comprehensive principle. Using the diversification of evaluation methods, and develop multi-level evaluation criteria. Affects the function of socialist education base education for many reasons, so effects of the socialist education base education evaluation should also. considering many factors. According to their different characteristics, make diversified evaluation criteria.

Due to the various levels of socialist education base, as well as the complexity of socialist education, the education effect evaluation mechanism of socialist education base should be diversified. Socialist education base establishment involves a number of departments, and socialist education itself is the whole society common responsibility. So education effect evaluation of socialist education base needs to multi-party participation.

\section{Conclusion}

In the central policy guidance and support from governments at all levels, socialist education base construction has remarkable success ${ }^{[10]}$. But the development of the problems exposed in the process, it should not be underestimated. In order to make full use of the resources of the socialist education base, to carry out various forms of socialist education and better carry out ideological and political education. In view of the various factors that affect the educational function of the socialist education base, a reform plan was proposed. In order to evaluate the reform plan, the experts' consultation was performed in this study. The consultation indicate that the reform of the education base must includes the following aspects. Strengthen of the construction of socialist education base. Encouraging of the education of the subject and object of scientific and effective use of the socialist education base. Establishing and improving of the education effect of socialist education evaluation mechanism.

\section{References:}

[1]. Li R. Media corruption: A Chinese characteristic[J]. Journal of business ethics, 2013, 116(2): 297-310.

[2]. Jianxin Lü. The Socialist Reform With Chinese Characteristics Under the Guidance of Chinese Spirit[J]. Cross-Cultural Communication,2015,115.

[3]. Hui ZHOU. Four Dimensions of Enhancing the Effectiveness of the College Students' Socialist Core Values Education[J]. Higher Education of Social Science,2015,95.

[4]. Xiao SUN. Three Dimensions of the Socialist Core Values Education of Adolescent[J]. Higher Education of Social Science,2015,95.

[5]. Zhu Jingwen. The Socialist Legal System with Chinese Characteristics: Its Structure, Features and Trends[J]. Social Sciences in China,2011,323.

[6]. Higher education base funding review: Final report[M]. Department of Education, Employment and Workplace Relations, 2011. 
[7]. Higher education base funding review: Final report[M]. Department of Education, Employment and Workplace Relations, 2011.

[8]. Fang C Z Q. Idea to Create Information Literacy Education Base in Colleges [J][J]. Information Research, 2013, 1: 013.

[9]. Fuchs-Schündeln N, Masella P. DP11093 Long-Lasting Effects of Socialist Education[J]. 2016.

[10]. Logics of socialist education: Engaging with crisis, insecurity and uncertainty[M]. Springer Science \& Business Media, 2012. 